\title{
Pesquisas e publicações sobre o processo de hidrogenação de óleos em margarinas utilizando catalisadores
}

\author{
Research and publication on the oil hydrogenation process in margarines using catalysts \\ Investigación y publicaciones sobre el proceso de hidrogenación de aceites em margarina con \\ catalizador
}

Recebido: 22/05/2021 | Revisado: 29/05/2021 | Aceito: 31/05/2021 | Publicado: 16/06/2021

\author{
Thuanny Silva Rodrigues \\ ORCID: https://orcid.org/0000-0001-7558-1565 \\ Instituto Federal de Educação, Ciência e Tecnologia do Triângulo Mineiro, Brasil \\ E-mail: thuannyrodrigues06@gmail.com \\ Letícia Vieira Castejon \\ ORCID https://orcid.org/0000-0002-6615-0146 \\ Instituto Federal de Educação, Ciência e Tecnologia do Triângulo Mineiro, Brasil \\ E-mail: leticiavieira@iftm.edu.br
}

\begin{abstract}
Resumo
O processo de hidrogenação de óleos e gorduras é um processo químico resultante de simultâneas reações, que tem por necessidade a presença de um catalisador de reação. A utilização de um metal no processo de hidrogenação contribui para a aceleração da reação desde que sejam empregados alguns fatores como pressão e temperatura adequados. As bibliografias disponíveis pesquisadas no Google Acadêmico apontam o níquel como sendo o elemento mais utilizado como catalisador de reação na indústria alimentícia, principalmente no processo de hidrogenação de óleos e gorduras para obtenção do produto margarina. Por apresentar as características de recurso não limitado e consequentemente baixo custo e segurança alimentar ao fim do processo de hidrogenação o níquel segue como a primeira opção das indústrias para a função de catalisador. Deste modo o objetivo do presente estudo será realizar uma busca literária sobre o processo de hidrogenação de óleos e gorduras e a utilização de catalisador de reação, de trabalhos publicados nos últimos cinco anos e disponíveis pela plataforma do Google Acadêmico, por se tratar de um processo amplamente utilizado na indústria alimentícia e principalmente para a elaboração de margarinas.
\end{abstract}

Palavras-chave: Metal; Matéria-prima; Processo químico.

\begin{abstract}
The hydrogenation process of oils and fats is a chemical process resulting from simultaneous reactions, which requires the presence of a reaction catalyst. The use of a metal in the hydrogenation process contributes to the acceleration of the reaction, provided that factors such as adequate pressure and temperature are employed. The available bibliographies researched on Google Scholar point to nickel as the element most used as a reaction catalyst in the food industry, mainly in the process of hydrogenation of oils and fats to obtain the margarine product. As it presents the characteristics of a non-limited resource and, consequently, low cost and food safety at the end of the hydrogenation process, nickel continues to be the industry's first option for the function of catalyst. Thus, the objective of the present study will be to carry out a literary search on the hydrogenation process of oils and fats and the use of reaction catalysts, from works published in the last five years and available through the Google Scholar platform, as it is a process widely used in the food industry and mainly for the manufacture of margarines.
\end{abstract}

Keywords: Metal; Raw material; Chemical process.

\section{Resumen}

El proceso de hidrogenación de aceites y grasas es un proceso químico resultante de reacciones simultáneas, que requiere la presencia de un catalizador de reacción. El uso de un metal en el proceso de hidrogenación contribuye a la aceleración de la reacción, siempre que se empleen factores como presión y temperatura adecuadas. Las bibliografías disponibles investigadas en Google Scholar apuntan al níquel como el elemento más utilizado como catalizador de reacción en la industria alimentaria, principalmente en el proceso de hidrogenación de aceites y grasas para la obtención del producto de margarina. Al presentar las características de un recurso no limitado y, en consecuencia, de bajo costo y seguridad alimentaria al final del proceso de hidrogenación, el níquel sigue siendo la primera opción de la industria para la función de catalizador. Así, el objetivo de este estudio será realizar una búsqueda literaria sobre el proceso de hidrogenación de aceites y grasas y el uso de un catalizador de reacción, a partir de trabajos publicados en los últimos cinco años y disponibles en la plataforma Google Academic, por ser un proceso Ampliamente utilizado en la industria alimentaria y principalmente para la preparación de margarinas.

Palabras clave: Metal; Materia prima; Proceso quimico. 


\section{Introdução}

A hidrogenação de óleos e vegetais é uma importante etapa de processamento na indústria de óleos e gorduras. A hidrogenação elimina parte das duplas ligações, enquanto uma proporção significativa de ligações remanescentes é isomerizada através da conversão cis/trans em relação à posição do ácido graxo. Este processo aumenta o ponto de fusão do material, melhora sua consistência para seu uso como margarina e aumenta sua resistência à oxidação (Coenen, 1976).

As reações de hidrogenação exigem sempre o emprego de catalisadores, de forma que, sem a presença dos mesmos, a reação ocorre somente em condições muito drásticas de temperatura e pressão, embora sob a perspectiva termodinâmica a reação de hidrogenação é extremamente favorável (Pinho \& Soares, 2013).

A catálise é um fenômeno que pode ocorrer em solução, em superfícies, em cavidades ou sítios específicos e o mecanismo depende do catalisador utilizado (Gates, 1992).

As reações de hidrogenação com catalisadores de níquel heterogêneos acontecem apenas em superfícies de níquel zero (Ni (0)), no entanto, este metal em estado de oxidação zero não é estável e quando armazenado ao ar é facilmente oxidado a óxido de níquel (NiO), que é inativo para reações de hidrogenação (Nishimura, 2001).

Deste modo o objetivo do presente estudo será realizar uma busca literária sobre o processo de hidrogenação de óleos e gorduras e a utilização de catalisador de reação, de trabalhos publicados nos últimos cinco anos e disponíveis pela plataforma do Google Acadêmico, por se tratar de um processo amplamente utilizado na indústria alimentícia e principalmente para a elaboração de margarinas.

\subsection{Hidrogenação}

O processo de hidrogenação de óleos e gorduras é um processo químico resultante de simultâneas reações, dentre elas podemos citar a saturação das duplas ligações em cadeias de ácidos graxos insaturados através da adição de átomos de hidrogênio $\left(\mathrm{H}_{2}\right)$ (Kheiri, 1984).

O processo de hidrogenação, ocorre em um reator fechado sob pressão e temperatura controladas com a presença de catalisadores metálicos, comumente o níquel é o mais utilizado por apresentar melhor relação de custo/benefício. A hidrogenação têm basicamente dois propósitos: o primeiro é de conferir uma maior e melhor estabilidade oxidativa ao óleo de soja aumentando a sua vida de prateleira e a segunda é a de converter o ponto de fusão dos óleos por necessidade do produto ou aumentar a sua aceitabilidade (Ribeiro, 2017).

O processo de hidrogenação é de suma importância para a indústria no sentido de promover a estabilidade do óleo, pois sendo altamente insaturado o óleo é susceptível a auto-oxidação, decomposição térmica e outras reações que afetam o sabor. Consequentemente, é desejável a hidrogenação parcial do óleo para aumentar seu shelf life (tempo de prateleira) e para aumentar a sua utilidade em função do espalhamento do produto obtido. Para muitos produtos tais como: manteigas, margarinas e gorduras de confeiteiro, a desejada maleabilidade e características de derretimento correspondem a óleos que são parcialmente hidrogenados. E a escolha do catalisador a ser utilizado na hidrogenação afeta as propriedades do produto final (Oliveira, 2008).

A hidrogenação é bastante utilizada pela indústria alimentícia afim de prolongar o prazo de validade de óleos ou para produzir as gorduras vegetais hidrogenadas. O que difere os dois processos é o grau de hidrogenação. Para conferir estabilidade aos óleos, a hidrogenação é realizada de forma parcial, assegurando um determinado grau de insaturação no produto final, de forma que a sua fluidez não seja comprometida e ele continue líquido a temperatura ambiente. Já para a produção de gorduras vegetais hidrogenadas, este processo é realizado de maneira quase completa, poucas são as insaturações restantes no produto (Pinho \& Soares, 2013). 


\subsection{Catalisadores dos processos de hidrogenação}

Catalisadores são materiais que aumentam a velocidade de uma reação química, sem que sejam consumidos no processo. A introdução do catalisador no sistema proporciona um novo percurso reacional energeticamente mais favorável, o que se traduz geralmente por uma diminuição da energia de ativação, com o consequente aumento da velocidade (Ganzaroli, 2014).

Uma reação catalisada acontece mais rapidamente e em condições mais brandas quando comparada a mesma reação na ausência de um catalisador. Além disso, a seletividade que pode ser alcançada com o uso de um catalisador diminui, ou até mesmo evita, a formação de subprodutos indesejáveis (Rothenberg, 2008).

Segundo Hagen (2006) os catalisadores são divididos basicamente em catalisadores homogêneos, heterogêneos e biocatalisadores. Os catalisadores homogêneos são os que estão presentes na mesma fase dos reagentes e produtos e que geralmente são reações realizadas em fase liquida; os catalisadores heterogêneos são os que estão presentes em fase diferente dos reagentes e produtos e os biocatalisadores são enzimas que apresentam uma atividade e seletividade maior em reações em condições brandas.

De acordo com Castilho (2008) o níquel é o catalisador seletivo mais utilizado industrialmente, sua adição no óleo é feita na proporção de 0,05 a $0,20 \%$, à temperatura de cerca de $180^{\circ} \mathrm{C}$ à pressão de 0,5 a 2,0 atm no processo de hidrogenação.

$\mathrm{O}$ níquel é um elemento natural da superfície terrestre, porém devido à sua acumulação no organismo pode causar efeitos nocivos para a saúde como a carcinogênese e a dermatite induzida (Ventura et al., 2016).

Segundo a Medicina complementar (2020) o níquel (Ni) é tóxico podendo causar: irritação gastrointestinal com náuseas, vômitos e diminuição do apetite; alterações neurológicas: dor de cabeça, vertigem; alterações musculares: fraqueza muscular; alterações cardíacas: palpitações; alergia: dermatite, rinite crônica, asma e outros estados alérgicos. O níquel inibe a ação da enzima superóxido dismutase que participa no processo de metabolização dos radicais livres. O excesso de níquel pode chegar a ter consequências graves como necrose e carcinoma do fígado e câncer de pulmão. Assim, o controle de qualidade efetivo deve ser sempre realizado após o processo de hidrogenação para se garantir a remoção desse metal do produto hidrogenado obtido e destinado ao consumo alimentar.

No caso de uma exposição aguda e recente ao níquel, o indicado nestes casos é a administração de um medicamento que contenha um agente ligante como o dietil-ditiocarbamato, que exerce a função de "captura" do metal, podendo minimizar os efeitos da contaminação. O indicado para detecção e confirmação da contaminação pelo níquel no organismo é a realização de exame de urina já que este metal é excretado através das vias urinarias, evidenciado uma concentração de 0,5 ppm já é considerado estado crítico (Homem, 2001).

\section{Metodologia}

Trata-se de um estudo de abordagem qualitativa que reflete as observações acumuladas durante o processo de pesquisa com o uso de recursos fotográficos e escritos (Ludke \& Andre, 2013).

O presente trabalho consistiu numa revisão bibliográfica de referências sobre a hidrogenação de óleos e, portanto, foi utilizada a base de dados virtuais digitalizados e disponibilizados pelo Google Acadêmico. Os termos de referências utilizados foram "hidrogenação óleos", "processo hidrogenação óleos", "catalisador hidrogenação óleos" e por fim, "catalisador hidrogenação óleos margarinas”. Os termos foram utilizados para direcionar a revisão aos artigos de maior relevância no período citado. 


\section{Resultados e Discussão}

Para a indexação "hidrogenação óleos" foram obtidos 1.946 artigos publicados do ano de 2017 a 2021 até o mês de abril, no idioma português, ou seja, quase nos 5 últimos anos. Na Figura 1, tem-se os números de publicações por ano pelo período dos 5 anos.

Figura 1: Quantidade de publicações sobre hidrogenação de óleos nos últimos cinco anos.

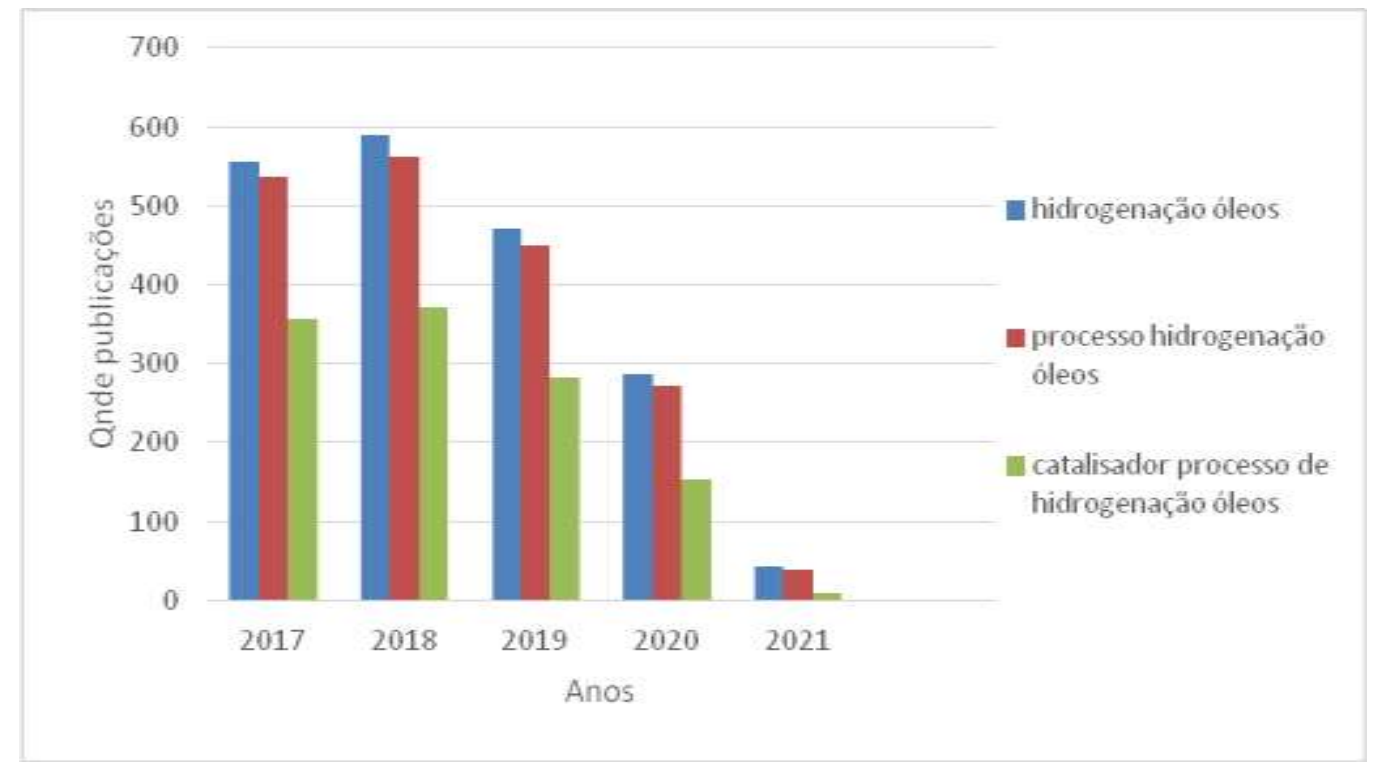

Fonte: Autoria própria (2021).

Nitidamente a pandemia do Covid-19 interferiu nas pesquisas científicas e consequentemente, nas publicações sobre o assunto de hidrogenação de óleos, processo e nos estudos sobre os catalisadores.

A busca de publicações com apenas os termos "hidrogenação óleos" ficou ampla, aparecendo artigos voltados à nutrição. Como o foco do trabalho é observar os artigos publicados sobre o processo de hidrogenação de óleos, inseriu-se o termo "processo" e a quantidade total de publicações diminuiu, diminuindo ainda mais quando refinamos as buscas inserindo o termo catalisador, utilizados no processo de hidrogenação. Verificou-se inúmeras publicações com os termos citados voltados á área de elaboração de biodiesel ou biocombustíveis, sendo necessário a inserção do termo margarinas às buscas para verificação da aplicação de catalisadores no processo de hidrogenação na área de conhecimentos em alimentos.

Do ano de 2017 a 2021 (abril) foram encontrados 133 artigos nos termos de busca "catalisador processo hidrogenação óleos margarinas", desse total, 43 artigos foram publicados em 2017, 37 artigos em 2018 e em 2019, em 2020 foram 15 artigos publicados e em 2021, apenas 1 artigo.

A plataforma do Google acadêmico ordena por relevância os artigos do período, ou seja, os mais citados, os quais serão referenciados no presente trabalho.

Luz em 2019, publicou dissertação de revisão bibliográfica sobre a Produção de Margarinas, citando a margarina como produto do processo de hidrogenação, no qual o gás hidrogênio e catalisador, sobre pressão, agitação e temperatura controladas, com o objetivo de saturar as duplas ligações dos ácidos graxos insaturados através da adição de átomos de hidrogênio. Em todo o processo, o catalisador apresenta fundamental importância: as moléculas de gás hidrogênio $\left(\mathrm{H}_{2}\right)$ se adsorvem na superfície do catalisador, reagindo com as moléculas do catalisador de metal, formando hidretos; as moléculas orgânicas também reagem com a superfície do catalisador, as ligações $\pi$ das ligações insaturadas entre carbonos são substituídas por novas ligações carbono - metal; um átomo de hidrogênio adsorvido se liga a um dos carbonos que era da 
ligação insaturada entre carbonos; o outro átomo de hidrogênio se liga ao outro carbono que fazia parte da ligação insaturada entre carbonos; a molécula saturada obtida e dessorvida da superfície do catalisador, deixando livre a superfície para outras moléculas insaturadas repetirem o mecanismo.

Em sua monografia Correia, 2019, aborda alternativas em substituição ao óleo de palma para a produção de margarina através dos métodos de mistura de óleos e/ou gorduras e interesterificação enzimática relacionando os efeitos na saúde humana e o seu consumo, os efeitos socioambientais causados pelo cultivo em especifico do óleo de palma, menciona as características desejáveis ao óleo para obtenção de um produto macio, cremoso e homogêneo em margarinas e similares e sugere outros processos de hidrogenação parcial como a hidrogenação eletroquímica, com processamento dos óleos a baixa temperatura (70 ${ }^{\circ} \mathrm{C}$ ), com formiato (sal do ácido fórmico) como eletro-catalisador, e com níquel e paládio, que resulta numa menor quantidade de ácidos gordos trans $(<10 \%)$.

De acordo com a dissertação Rosa, 2017, apresenta a definição de catálise como a aceleração de reações químicas pela presença de uma substância que não é consumida na reação e indica que um dos principais setores da economia mundial, a indústria alimentícia, depende de algum processo catalítico. Justificou seu trabalho ao utilizar a sílica como suporte ao níquel, devido à disponibilidade e o custo dos catalisadores a base de metais como, por exemplo, a platina, de recurso natural limitado gerando por consequência alto custo. Concluiu que o catalisador comercial mais utilizado nas reações de hidrogenação de óleos vegetais para a produção de margarina é o níquel Raney observado na Figura 2 que se comparado à platina como um metal barato e disponível, observada a exigência do emprego de condições de temperatura e pressão para sua utilização.

Figura 2: Forma física do catalisador de níquel (granulado).

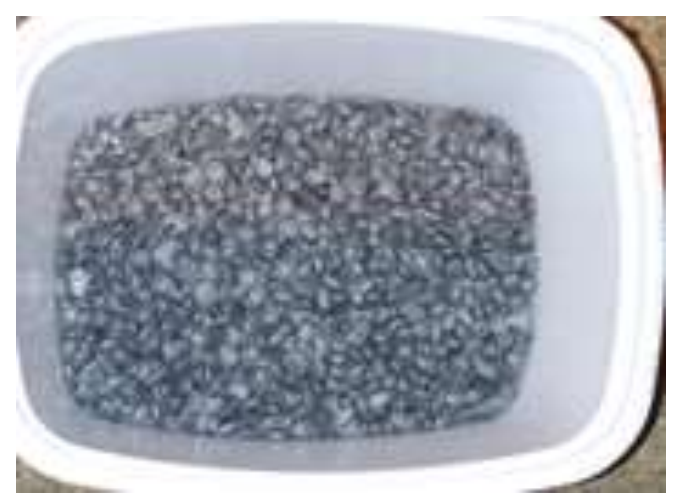

Fonte: Autoria própria (2021).

Zaramello, em 2017, verificou em vários trabalhos sobre hidrogenação, que a grande parte utiliza metais nobres como catalisadores, rutênio, ródio, platina, irídio e paládio. Mesmo com os altos custos relacionados ao uso destes metais, a utilização de metais de transição abundantes da primeira linha da tabela periódica como ferro, cobalto e níquel torna a catálise mais atraente do ponto de vista econômico e vem sendo explorada. Uma alternativa à redução do custo estudada foi a aplicação de nanopartículas de níquel, no qual aumentou a geração de olefinas, compostos carbonílicos e nitrocompostos. Explicou que o interesse nesses compostos consiste nos produtos gerados, que são relevantes na indústria farmacêutica e química de aromas, da mesma forma, que a redução de nitrocompostos é importante do ponto de vista industrial e ambiental.

Araújo em 2018, expôs em seu trabalho de conclusão de curso que a gordura destinada à produção de margarina é resultante do processo em que óleos comestíveis foram submetidos ao processo de hidrogenação, tornando-se gorduras saturadas como exemplificado na Figura 3. O níquel foi o metal utilizado como catalisador da reação e por este motivo deve ser aplicado um controle rígido para que traços residuais não estejam presentes na gordura produzida, pois o níquel quando 
ingerido em altas concentrações pode causar efeitos tóxicos ao organismo humano. Portanto, foi proposto novo método de detecção eletro analítico de níquel em alimentos industrializados, no qual teve-se resultados satisfatórios contribuindo para a área de segurança alimentar dos produtos como margarinas e gorduras vegetais hidrogenadas.

Figura 3: Gordura saturada hidrogenada em estado líquido.

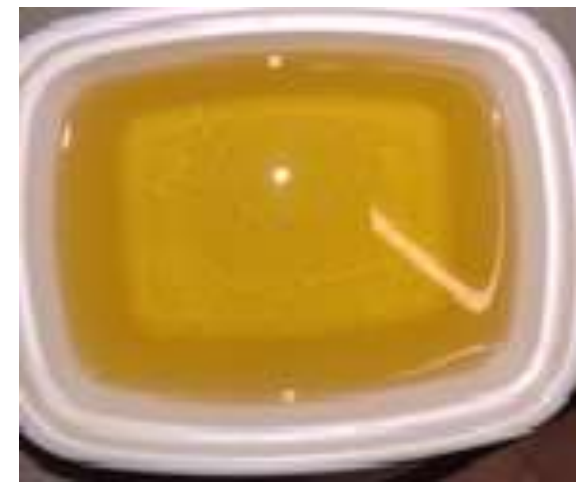

Fonte: Autoria própria (2021).

Na Figura 4 tem-se a fotografia dos filtros, malhas metálicas de pressão vertical, do tipo PZ80S Panzer Weave, de espessuras dos fios de 0,2 e 0,4 mm e retenção nominal de aproximadamente 80 mícron, normalmente utilizadas nas indústrias para a remoção do níquel utilizado como catalisador seletivo do processo de hidrogenação (Filtração em filtros de pressão verticais, 2021).

Figura 4: Vista superior de um filtro vertical, onde as placas dispostas lado a lado exercem a função de retenção do catalisador.
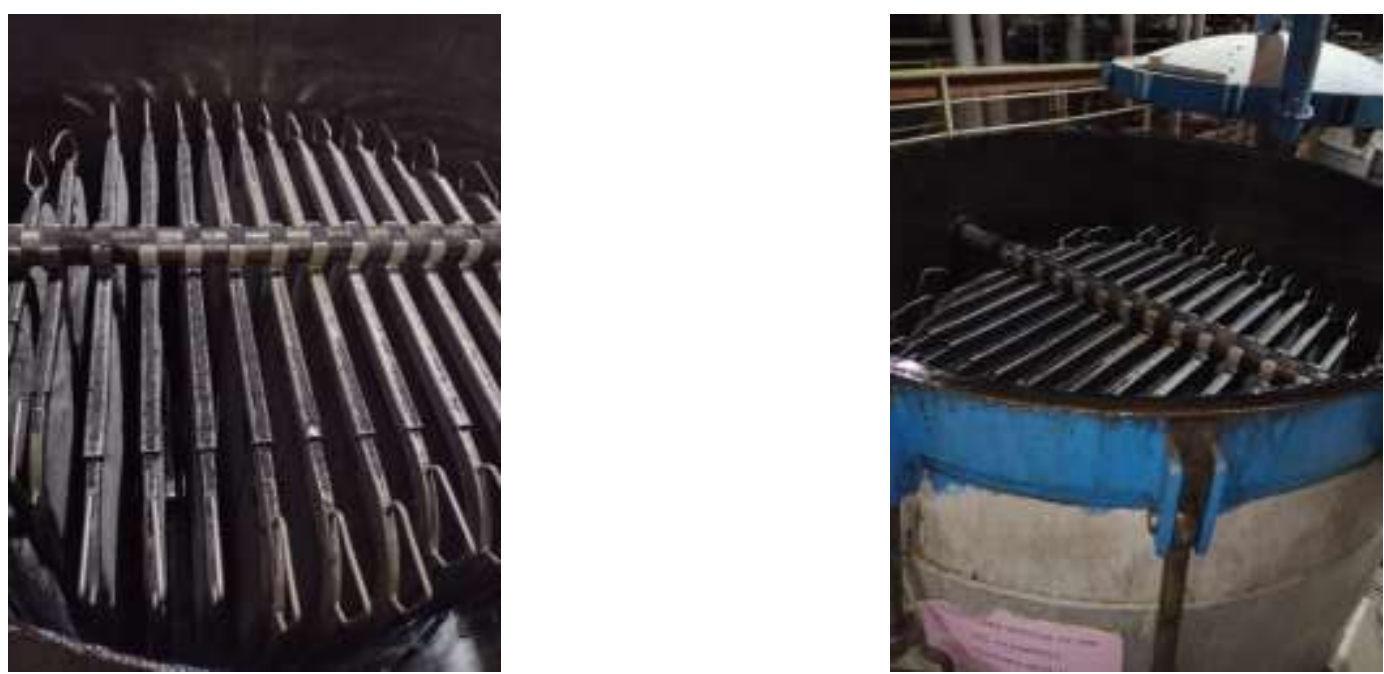

Fonte: Autoria própria (2021).

Na revisão não foi encontrada nenhuma publicação, durante o período verificado, de 2017 a 2021 , sobre a remoção do catalisador do processo de hidrogenação. No entanto, sabe-se que as indústrias utilizam silicatos minerais amorfos, piro expandidos e inertes para a aglutinação e retenção dos catalisadores quando a gordura aquecida hidrogenada passa pelo filtro vertical.

A dissertação de Oliveira em 2008 traz maiores informações sobre o uso desses silicatos, onde foi estudado a sílica 
mesoporosa ordenada. Descreveu que esses materiais são suportes para catálise e para a remoção dos catalisadores, e, portanto, existem os suportes catalíticos e os inertes. A remoção desses suportes se dá na filtração do catalisador e para o reaproveitamento dos catalisadores, eles são calcinados a $300^{\circ} \mathrm{C}$, ocorrendo a pirólise completa dos suportes. Dentre os suportes mais utilizados estão o carvão ativado, a sílica gel, as aluminas ativadas, as argilas naturais e as sílicas-aluminas. O uso depende da inercia ou não do material de suporte, da catalisação e do catalisador suportado, da reação, da porosidade do material, da transferência de calor e outros fatores mais específicos.

\section{Considerações Finais}

O emprego de um catalisador é imprescindível para que ocorra a reação no processo de hidrogenação de óleos e gorduras e o metal comumente utilizado na indústria alimentícia, principalmente nos processos de obtenção de margarinas é o níquel devido a sua disponibilidade e baixo custo se comparado a outros metais, além de apresentar-se seguro do ponto de vista alimentar desde que aplicado o controle de qualidade efetivo ao fim do processo de hidrogenação.

As pesquisas e publicações citadas apresentam o metal níquel como sendo o elemento mais viável na utilização como catalisador no processo de hidrogenação de margarinas, visando pesquisas futuras seria interessante e de extrema relevância para a área de alimentos a busca por alternativas em substituição ao níquel que apresente características semelhantes de abundância de recursos, segurança alimentar e baixo custo para a indústria.

\section{Referências}

Araújo, N. C. (2018). Desenvolvimento de metodologia eletroanalítica para determinação de níquel em alimentos. 55p. Trabalho de Conclusão de Curso (Graduação em Engenharia de Alimentos) - Universidade Federal de Uberlândia, Patos de Minas.

Castilho, C. M. (2008). Obtenção de gorduras low trans por interesterificação química. Tese (doutorado). Universidade Estadual de Campinas. Departamento de Engenharia de Alimentos. Programa de pós-graduação Stricto Senso em Tecnologia de Alimentos. 278p.

Coenen, J. W. E. (1976). Hydrogenation of edible Oils. Journal of the American Oil Chemists' Society. 53, (6), 382-9.

Correia, F. D. (2019). Substituição do óleo de palma na produção industrial de alimentos. 59p. Monografia. Faculdade de Ciências da Nutrição e Alimentação. Universidade do Porto.

Filtração em filtros de pressão verticais. (2021) . http://dorsa-caranti.com.br/wp-content/uploads/2020/06/FILTRA\%C3\%87\%C3\%83O-EM-FILTROS-DEPRESS\%C3\%830-VERTICAIS.pdf.

Ganzaroli, R. D. (2014). Hidrogenação do Tolueno m fase líquida com Catalisadores de Ni e Ru suportados em Alumina: Efeitos do pH e da Natureza do Agente Redutor Empregados na Preparação dos Sólidos por Impregnação Úmida. 131p. Dissertação (Mestre em Engenharia Química) - Universidade Estadual de Campinas, São Paulo.

Gates, B. (1992). Catalytic. Singapore: Jonh Wiley \& Sons.

Hagen, J. (2006). Industrial catalysis: a pratical approach. Second. Ed. Weinheim: Wiley-VCH Verlag.

Homem, E. M. (2001). Remoção de chumbo, níquel e zinco em zeólita utilizando sistemas de leito fluidizado. 132p. Dissertação (Mestre em Engenharia Química) - Universidade Estadual de Campinas, São Paulo.

Kheiri, M. S. A. (1984). Hydrogenation. Porim technology. (10), 52p.

Ludke, M. \& Andre, M. E. D. A. (2013). Pesquisas em educação: uma abordagem qualitativa. São Paulo: E.P.U.

Luz, P. H. D. M. (2019). Produção de margarinas: descrição de processo, características e performance de produto. 41p. Dissertação. Faculdade de Engenharia Química. Universidade Federal de Uberlândia (UFU), Uberlândia.

Medicina complementar. (2020). http://www.medicinacomplementar.com.br/pop_artigo.html?pagina=in-m0011.

Nishimura, S. (2001). Handbook of heterogeneous catalytic hydrogenation for organic synthesis. New York: John Wiley \& Sons, Inc.

Oliveira, N. A. (2008). Síntese e Caracterização de Catalisadores de Níquel Suportados em Sílica Mesoporosa Altamente Ordenada para Hidrogenação de Óleos Vegetais. 124p. Dissertação (Mestre em Química Analítica) - Universidade de São Paulo, São Paulo.

Pinho, D. M. M. \& Suarez, P. A. Z. (2013). A Hidrogenação de Óleos e Gorduras e suas Aplicações Industriais. Revista Virtual de Química, Niterói. 5, (1), 47-62. 
Research, Society and Development, v. 10, n. 7, e13810716392, 2021

(CC BY 4.0) | ISSN 2525-3409 | DOI: http://dx.doi.org/10.33448/rsd-v10i7.16392

Ribeiro, D. T. (2017). Comparação entre os métodos de determinação de índice de iodo para gordura de soja parcialmente hidrogenada. 31p. Trabalho de Conclusão de Curso (Graduação) - Universidade Tecnológica Federal do Paraná, Campo Mourão.

Rosa, T. (2017). Obtenção de nanopartículas de níquel suportadas em sílica via pulverização catódica: preparação e atividade catalítica. 91p. Dissertação (Mestrado em Química) - Instituto de Química, Universidade de São Paulo, São Paulo.

Rothenberg, G. (2008). Catalysis: Concepts and Green Aplications. Weinheim: Wiley-VHC.

Ventura, M. et al. (2016). Nickel occurrence in food consumed in Portugal: preliminary results of TDS project pilot. Alimentação e Nutrição, Portugal, (3), 10-3.

Zaramello, L. (2017). Síntese, caracterização e aplicação de nanopartículas de níquel em reações de hidrogenação de compostos carbonílicos. Tese (doutorado). Universidade Federal de Santa Catarina. Centro de Ciências Físicas e Matemáticas. Programa de Pós-graduação em Química. 134p. 